Supporting Information

\title{
Ion current rectification at nanopores in glass membranes
}

Henry S. White and Andreas Bund

Some details on the numerical procedure.

The COMSOL Multiphysics Software (Version 3.3.0.511) was used with the following modules:

- Electrostatic (Poisson equation)

- Nernst-Planck without Electroneutrality

- Imcompressible Navier Stokes (only in problems involving electro-osmotic flow)

UMFPACK was used as the linear system solver. A typical mesh is shown in Fig. SI1.

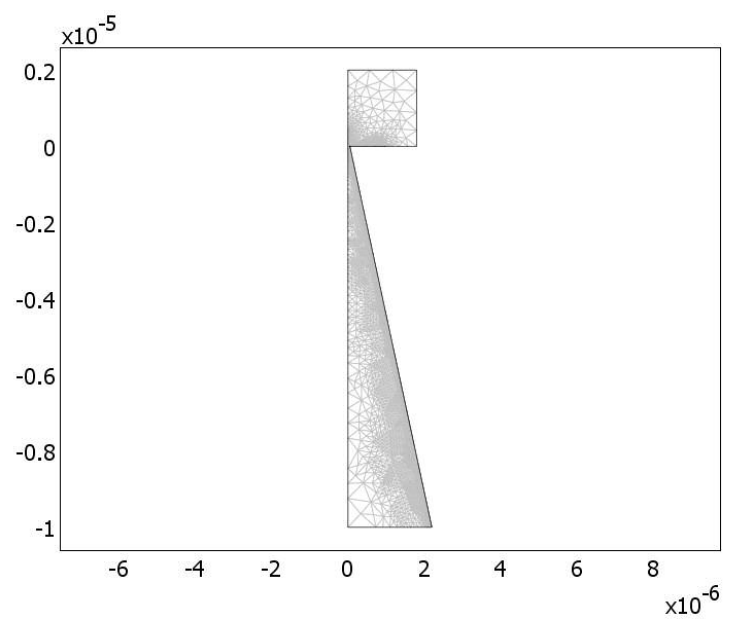

Fig. SI-1: A typical mesh used for the numerical simulation. At the pore walls the mesh size is refined to resolve the features of the electrical double layer.

The number of degrees of freedom was typically 125,000 for a simulation of the Poisson-Nernst-Planck equations. When in addition the momentum balance (NavierStokes equation) was solved the number of degrees of was slightly above 200,000. Simulation times on dual core Athlon XP 4200+ with 2GB RAM were a few hundred seconds. 
Electroosmotic flow in conical glass nanopores.

With increasing surface charge the electro-osmotic flow (EOF) increases. For $\sigma=-1$ $\mathrm{mC} / \mathrm{m}^{2}$ the pressure drops across the pore mouth are ca. $-300 \mathrm{~Pa}$ and $450 \mathrm{~Pa}$, for biases of $-0.5 \mathrm{~V}$ and $+0.5 \mathrm{~V}$, respectively (Fig. SI-2).

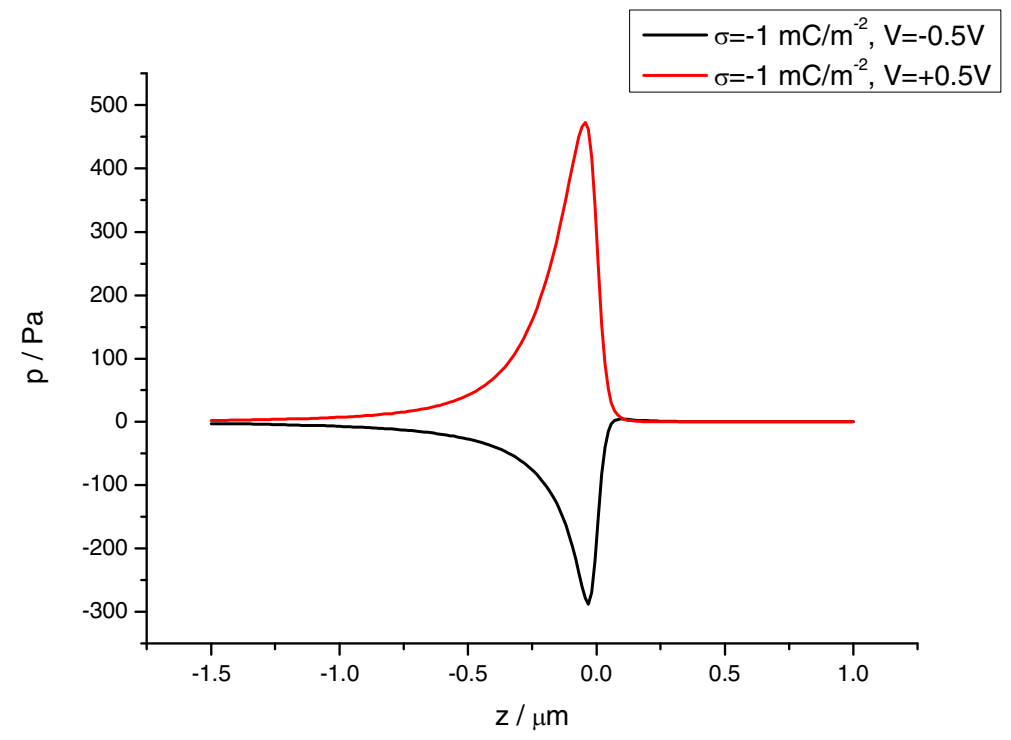

Fig. SI-2: Pressure along the centerline $(\mathrm{z}=0)$ for a $50 \mathrm{~nm}$ mouth radius nanopore base radius $2.2 \mu \mathrm{m}$, length $10 \mu \mathrm{m}$, half cone angle $12^{\circ}$, surface charge $-1 \mathrm{mC} / \mathrm{m}^{2}$ ) in $1 \mathrm{mM} \mathrm{KCl}$.
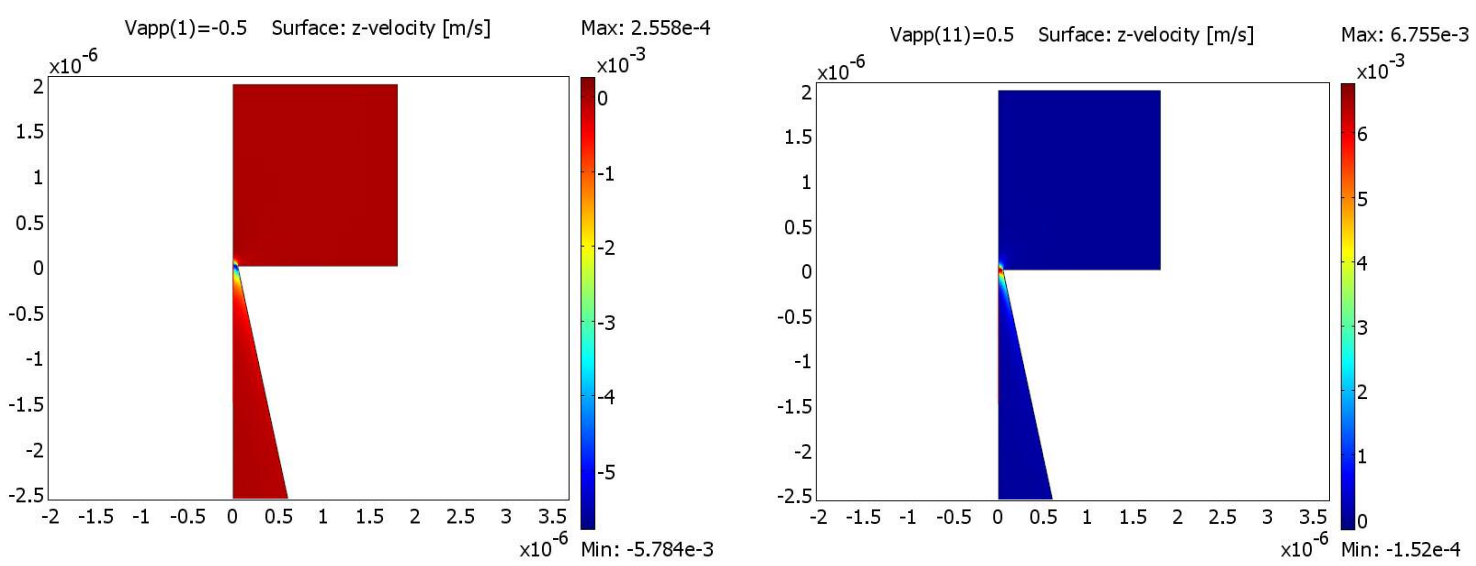

Fig. SI-3: z-component of the velocity in the region around the pore mouth $(50 \mathrm{~nm}$ radius) for a surface charge of $-1 \mathrm{mC} / \mathrm{m}^{2}$ for $-0.5 \mathrm{~V}$ (left) and $+0.5 \mathrm{~V}$ bias (right).

The maximum velocities in $z$ direction (along the symmetry axis of the pore) are $v_{z}=$ $5.8 \mathrm{~mm} / \mathrm{s}$ and $\mathrm{v}_{\mathrm{z}}=6.8 \mathrm{~mm} / \mathrm{s}$ for biases of $-0.5 \mathrm{~V}$ and $+0.5 \mathrm{~V}$, respectively (Fig. SI-3). 
If the surface charge increases to $-5 \mathrm{mC} / \mathrm{m}^{2}$, the absolute values of the pressure drop increase to $-500 \mathrm{~Pa}$ and $2300 \mathrm{~Pa}$ for biases of $-0.5 \mathrm{~V}$ and $+0.5 \mathrm{~V}$, respectively (Fig. $\mathrm{SI}-4)$. The corresponding maximum values of $\mathrm{v}_{\mathrm{z}}$ are $-18.2 \mathrm{~mm} / \mathrm{s}(-0.5 \mathrm{~V}$ bias $)$ and $24.6 \mathrm{~mm} / \mathrm{s}(+0.5 \mathrm{~V}$ bias). For a positive bias the EOF is directed from the base through the mouth out of the pore. For negative bias, fluid flows through the mouth from the outside to the inside of the pore. Therefore, for high flow rates under these conditions the pressure rises in front of the pore mouth (Fig. SI-4, black curve).

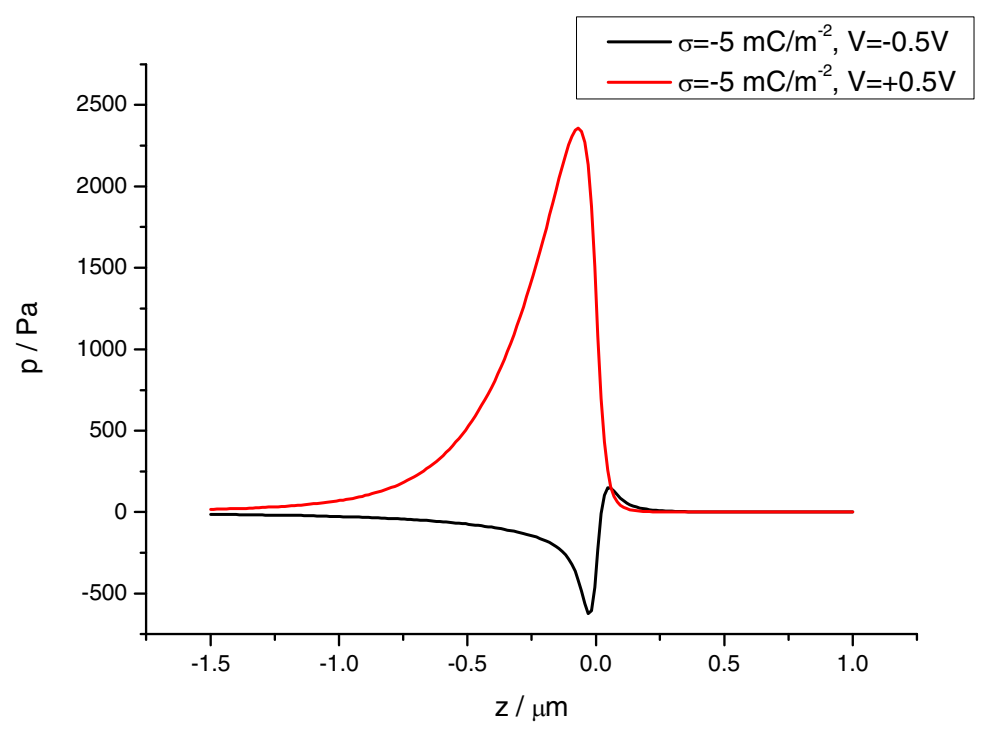

Fig. SI-4: Pressure along the centerline $(\mathrm{z}=0)$ for a $50 \mathrm{~nm}$ mouth radius nanopore base radius $2.2 \mu \mathrm{m}$, length $10 \mu \mathrm{m}$, half cone angle $12^{\circ}$, surface charge $-5 \mathrm{mC} / \mathrm{m}^{2}$ ) in $1 \mathrm{mM} \mathrm{KCl}$.
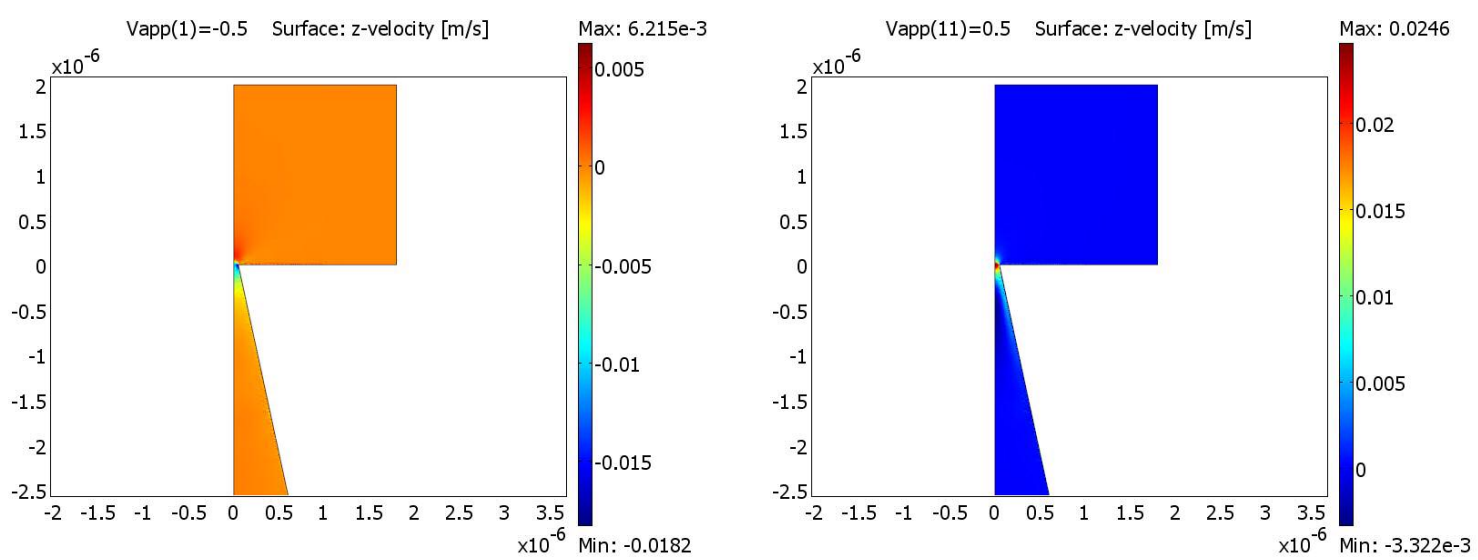

Fig. SI-5: z-component of the velocity in the region around the pore mouth $(50 \mathrm{~nm}$ radius) for a surface charge of $-5 \mathrm{mC} / \mathrm{m}^{2}$ for $-0.5 \mathrm{~V}$ (left) and $+0.5 \mathrm{~V}$ bias (right). 